\title{
Methodology for infrared spectroscopy analysis of sandwich multilayer samples of historical materials
}

\author{
Ivana Kopecká* and Eva Svobodová
}

\begin{abstract}
Introduction: Multilayer materials of cultural heritage such as historical materials and artwork are analysed as cross-section samples using microscopy and FTIR microscopy. Most commonly, these samples are embedded in synthetic resin, ground and polished. During this process, there is a high potential for the synthetic resin to contaminate the sample. The resin penetrates into the open pores or cracks in the sample, or solvent of the resin can partially dissolve some layer of the analysed sample. In both cases, the presence of synthetic resin significantly distorts the results of analysis, particularly the analysis of peripheral layers, which are of course the most contaminated. Interpretation of the FTIR spectra of individual layers is very difficult; it can be ambiguous and largely subjective. Moreover, analysed layers are usually a mixture of substances, where the studied substance (for example organic binder) is present as a minor component.

Results: Due to potential contamination of samples processed with the aforementioned method, a new method of preparing samples is desired, one in which contamination of the sample caused by the embedding material would be eliminated. This paper compares the advantages and limits of different methods of sample preparation before analysis; methods which would eliminate the contamination of analysed materials. Various analytical methods and different procedures used for sample preparation are discussed. The most successful of the tested insulation methods proved to be that of pressing the sample in $\mathrm{KBr}$ pellet, gold sputtering and carbon coating or anticipatory treatment by cyclododecane solution before embedding the sample in synthetic resin.
\end{abstract}

Conclusion: It can be concluded that these procedures eliminate contamination of the analysed sample regardless of its nature and morphology. This conclusion was confirmed by an analysis of real samples.

Keywords: FTIR microscopy; Sandwich multilayer samples; Cross-section; Insulation of synthetic resin; Sample preparation

\section{Introduction}

In the field of conservation-restoration of works of art and in the forensic analysis of works of art it is often necessary to analyse multilayer materials (e.g. formation of paint layers of paintings, polychrome paint ...). In these cases it is possible to take only a very small sample for analysis. The first step is the creation of cross-section for observation under a microscope before other analysis. The sample is usually embedded in synthetic resin (polyacrylic [1], polyesters [1-4] or epoxy [2,5,6]).

During the formation of the cross-section, the embedding material has the potential to contaminate the sample $[3,7]$. With more porous samples, the embedding

* Correspondence: ivana.kopecka@ntm.cz

National Technical Museum, Kostelní 42/1320, 17078 Prague 7, Czech Republic material penetrates into the open pores or cracks, especially in the peripheral layers of the sample. In some cases solvent of the resin can also dissolve some of the analysed layer of the sample. This contamination does not play any role at the optical observations or in the inorganic analysis, but it may significantly distort analysis of organic materials. This implies the need for other sample preparation, which would eliminate the contamination caused by the embedding resin.

FTIR analysis of the discrete layers is one possible solution. At first, the layers of a multilayer sample must be separated using a microtome $[8,9]$ or a scalpel under a microscope. This method is very laborious and rarely applicable, taking into account the size of the analysed samples and its poor consistency.
Springer

(c) 2014 Kopecká and Svobodová; licensee Springer. This is an Open Access article distributed under the terms of the Creative Commons Attribution License (http://creativecommons.org/licenses/by/4.0), which permits unrestricted use, distribution, and reproduction in any medium, provided the original work is properly credited. The Creative Commons Public Domain Dedication waiver (http://creativecommons.org/publicdomain/zero/1.0/) applies to the data made available in this article, unless otherwise stated. 
Contamination of the sample can be reduced by selecting the right embedding material and technique. There are two commonly used embedding techniques. When the molecular structure of the resin is high enough to not penetrate the samples' pore system, the technique of embedding the sample in a hardening resin on a hardened bed can be used. Likewise, the technique of fixing the sample to the wall of the mold and then cutting the sample once the resin has cured can also be used. Both methods, however, do not guarantee that the embedding of the resin will not contaminate the sample. As we have gained from former experience in this field, the influence of the viscosity and rheological properties of embedding materials on the potential for contamination of samples is not significant (except for samples with extremely high open porosity).

Another way to reduce the potential contamination of the sample with resin is the barrier method. This involves the covering of the sample by an insulating material prior to embedding the sample in synthetic resin. The authors [3] tested various methods to prevent the infiltration and to minimize contamination with resin using very thin layer of Rhoplex AC-33 (acrylic dispersion) thickened with fumed silica. Another successful barrier is cyclododecane $[2,10]$ which has been commonly used as a temporary consolidant and barrier coating in conservation processes.

When fixing a sample, synthetic resin may be substituted by halide salts (i.e. potassium bromide, sodium chloride or silver chloride etc.). These halide salts are inactive in infrared light. A cross-section of a multi-layer sample may be made by pressing the sample into the halide salt pellets [8-14]. This method eliminates any contamination of the studied sample. However, the pellet is very hydroscopic, and therefore must be kept in a desiccator for long-term storage.

\section{Experimental}

\section{Sample preparation}

Eleven samples of paint layers were taken from the surface of one historical railway car from the collection of the National Technical Museum in Prague, Czech Republic. From these samples, eleven cross-sections were prepared using different methods:

1. Sample $\mathbf{K B r}$ was pressed with $\mathrm{KBr}$ powder (Acros Organics, Belgium) into a conventional $13 \mathrm{~mm}$ diameter disk using Die Kit (PIKE Technologies, USA) and $\mathrm{H}-62$ vacuum press (Trystom, Czech Republic) under $30 \mathrm{kN}$ of pressure for 2 minutes. The sample was cut through the center by two parallel cuts and pressed again into the new pellet, perpendicularly to the direction of the first compression.
2. Sample $\mathbf{D}$ was embedded into the acrylic resin Dentacryl (SpofaDental, Czech Republic).

3. Before embedding into the Dentacryl samples DC and $\mathbf{D C t}$ were immersed into the cyclododecane (Sandragon, Czech Republic) either in the form of melt (sample $\mathbf{D C t}$ ) or as a solution in diethylether p. a. (Lach-Ner, Czech Republic) in case of sample DC.

4. Sample $\mathbf{P}$ was embedded into the polyester resin Polylite (Reichhold, USA).

5. Before being embedded into the Polylite, samples PCt and PC were immersed into melted cyclododecane and a solution in diethylether, respectively.

6. Sample PS was first immersed into a potassium liquid glass (Water glass Inc., Czech Republic [15]) and then embedded into the Polylite resin.

7. Sample $\mathbf{P H}$ was first immersed into an aqueous dispersion of polyvinyl acetate Herkules (Druchema, Czech Republic) and then embedded into the Polylite resin.

8. Before being embedded in the Polylite resin, samples $\mathbf{P}-\mathbf{C}$ and $\mathbf{P}-\mathbf{A u}$ were either coated by carbon (sample $\mathbf{P}-\mathbf{C}$ ) or sputtered by gold (sample $\mathbf{P}-\mathbf{A u}$ ) at the Institute of geochemistry, mineralogy and mineral resources of Charles University in Prague by Prof. Richard Přikryl.

All cross-sections (excluding sample $\mathbf{K B r}$ ) were ground and polished under water by polisher/grinder Saphir 320 (ATM, Germany) with silicon carbide waterproof abrasive papers WS-Flex 18-C P600 and P1200 (Hermes Schleifmittel, Germany).

A sample of paint layers of the painting Madonna from the church of St. Thomas in Brno in the Czech Republic was divided in two parts. The preparation of its crosssections followed the preparation methods of sample $\mathrm{KBr}$ (sample no.1 (KBr) - incarnate) and sample P (sample no.1 (Polyester resin) - incarnate), respectively.

The preparation of all samples is summarized in Table 1.

\section{Analytical techniques}

Cross-sections have been observed using optical fluorescence stereomicroscope Leica M165 FC (Leica Microsystems, Switzerland) equipped with various objectives (zoom 16:1; magnification $7.1 \times-115 \times)$. Nicolet iN10 MX FTIR microscope (Thermo Scientific Inc., USA) with liquid nitrogen cooled MCT-A detector has been used for the measurements by ATR technique with multi-coated, conical shape germanium tip crystal (350 micron spherical finish, single reflection, throughput $>50 \%, 27^{\circ}$ average angle). Each spectrum has been achieved in the range of 4000$650 \mathrm{~cm}^{-1}$ at a spectral resolution of $8 \mathrm{~cm}^{-1}$ and with 128 scans on the average using Omnic software (Thermo Scientific Inc., USA). 
Table 1 A summary of prepared samples

\begin{tabular}{llll}
\hline Sample name & Barrier method & Embedding method & Grinding/Polishing \\
\hline Sample KBr & No & KBr powder & Manually, dry \\
Sample D & No & Dentacryl (acrylic resin) & Wet \\
Sample DC & Cyclododecane - solution & Dentacryl (acrylic resin) & Wet \\
Sample DCt & Cyclododecane - melt & Dentacryl (acrylic resin) & Wet \\
Sample P & No & Polylite (polyester resin) & Wet \\
Sample PC & Cyclododecane - solution & Polylite (polyester resin) & Wet \\
Sample PCt & Cyclododecane - melt & Polylite (polyester resin) & Wet \\
Sample PS & Liquid glass & Polylite (polyester resin) & Wet \\
Sample PH & Aqueous dispersion of polyvinyl acetate & Polylite (polyester resin) & Wet \\
Sample P-C & Carbon coating & Polylite (polyester resin) & Wet \\
Sample P-Au & Gold sputtering & Polylite (polyester resin) & Wet \\
Sample no.1 (Polyester resin) & No & Polylite (polyester resin) & Wet \\
Sample no.1 (KBr) & No & KBr powder & Manually, dry \\
\hline
\end{tabular}

\section{Results and discussion}

During the analysis of the cross-section sample taken from the paint layers of the historical railway car (collection of the National Technical Museum, Prague, Czech Republic) different barrier methods to prevent the infiltration of embedding materials in the samples were used. The two embedding materials used were synthetic resin [polyacrylic resin (Dentacryl) and polyester resin (Polylite)]. First, samples were fixed into the resin without any protective layers to verify the infiltration of embedding resins into the layers of analysed sample. Next, before embedding, samples were covered by a protective layer. The barrier layers studied were: cyclododecane in melted form and as a solution, liquid glass, dispersion of polyvinyl acetate (Herkules), a coat of sputtered gold and a coat of carbon.

Infiltration of the sample had been verified comparing the infrared spectra (ATR mode with germanium crystal) of the peripheral layer of the sample (in Figure 1 marked with number 1 ) which was embedded into synthetic resin and another sample which had been pressed in $\mathrm{KBr}$ pellet. This layer was characterized separately by the methods of FTIR micro spectroscopy (ATR mode - see Experimental, and transmittance mode - the first layer was scraped off from the surface of the sample, mixed with $\mathrm{KBr}$ powder, pressed into a pellet and analysed in the range of 4000$675 \mathrm{~cm}^{-1}$ at a spectral resolution of $8 \mathrm{~cm}^{-1}$ with 128 scans), Raman micro spectroscopy (at the National Gallery in Prague by Ing. Radka Šefců, DXR Raman Microscope Nicolet, $780 \mathrm{~nm}$ laser, exposure time of 5 minutes, the range of $3300-50 \mathrm{~cm}^{-1}$ at a resolution of $2 \mathrm{~cm}^{-1}$ Raman shift), SEM-EDX (at the Department of Mechanics of the Faculty of Civil Engineering, the Czech Technical University in Prague by Dr. Lubomír Kopecký, specification of the method in [16]) and GS-MS (at the Kunsthistorisches Museum in Vienna by Dr. Václav Pitthard, specification of the method in [17] - paragraph Analytical Procedure). Results of all these methods confirmed that this layer consists of titanium white (rutile) and phthalocyanine blue bound with linseed oil. The presence of vibration spectral
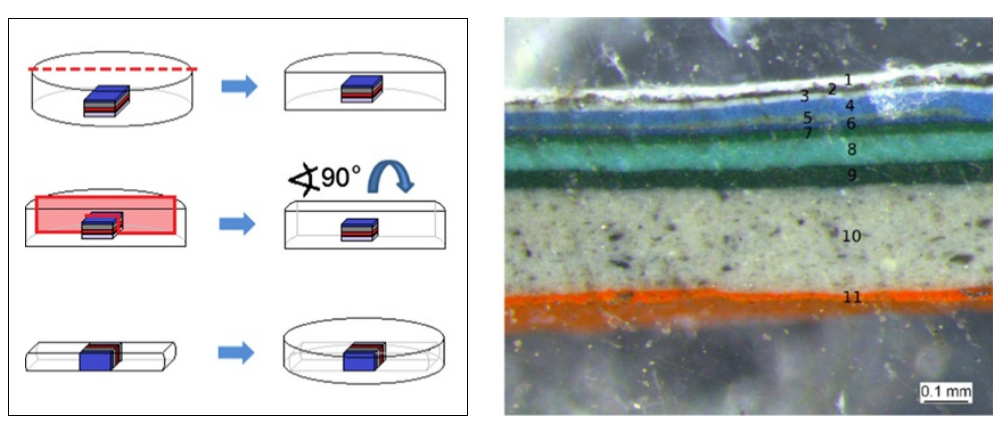

Figure 1 Multilayer sample pressed twice in a $\mathbf{K B r}$ pellet. Scheme (left): First the multilayer sample is pressed into the flat $\mathrm{KBr}$ pellet. The middle part of the pellet is precisely cut by two parallel cuts. This part is pressed again into the new pellet, perpendicularly to the direction of compression of the original pellet; Microscopic image of the sample of paint-layers of historical railway car in KBr pellet (right). 
bands characteristic for the synthetic resin, used as the embedding material, appeared in the spectrum of this first layer of the analysed sample confirms the infiltration of embedding material in the sample.

The contamination of sample with embedding material may also occur as a result of smearing during dry or wet polishing. When such smearing does occur, all layers of the sample, peripheral layers as well as inner layers, are affected the same way without any distinction. Nevertheless, the contamination of inner layers of the sample with synthetic resin had been tested as well. The infrared spectra of these layers are not distorted with strong vibration bands of synthetic resin (the concordance of these with the infrared spectra of inner layers of the sample $\mathrm{KBr}$ is more than $92 \%$ on the average, where the concordance between first layers is only $78 \%$ on the average). On the contrary, the use of liquid glass and Herkules as a barrier method can show a higher smearing effect on the contamination of surface of the sample than the synthetic resin.

\section{$\mathrm{KBr}$ pellet}

The pressing of the sample into the $\mathrm{KBr}$ pellet was chosen as the comparative method - without any contamination.
The preparation of pellets for FTIR microscopy may proceed in several ways, depending on the size and nature of sample:

1. In the $\mathrm{KBr}$ pellet, layers cut flat at an angle are inserted so that all layers are gradually revealed.

2. Multilayer sample is pressed into the $\mathrm{KBr}$ pellet perpendicularly to the plane of the layers and then the pellet is carefully ground down to the reveal the cross-section of the sample material.

3. First, the multilayer sample is pressed into the flat $\mathrm{KBr}$ pellet. The middle part of the pellet (the sample in pellet) is precisely cut by two parallel cuts. This part is pressed again into the new pellet, perpendicularly to the direction of compression of the original pellet (Figure 1).

Results of analyses of samples prepared in this way are satisfactory and definitely undistorted by the presence of any auxiliary substances. FTIR spectrum of the sample fixed in $\mathrm{KBr}$ pellet is presented in Figures 2 and 3 (the upper red spectrum - sample $\mathrm{KBr}$ ) and was taken as reference for the other barrier methods.

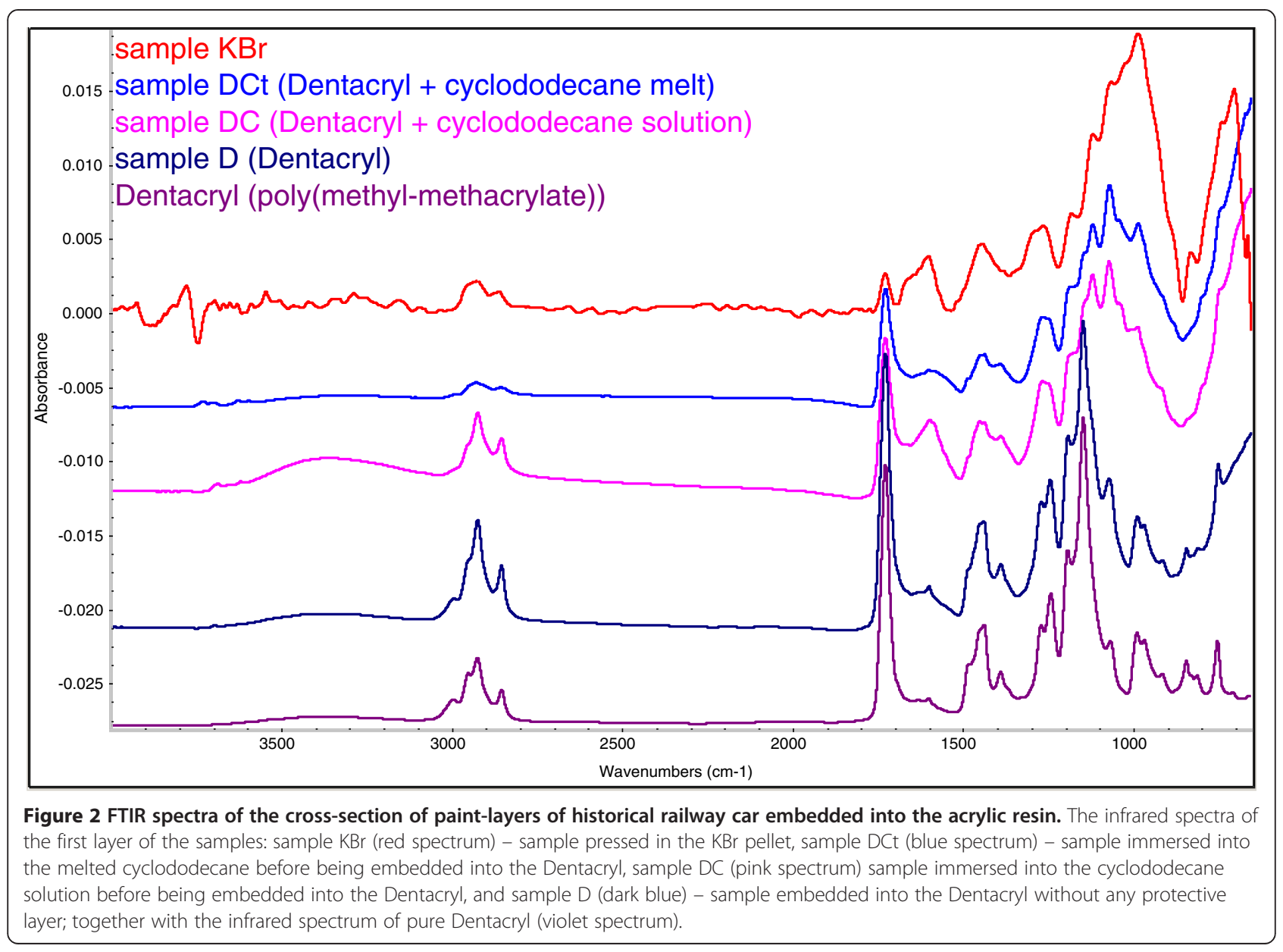




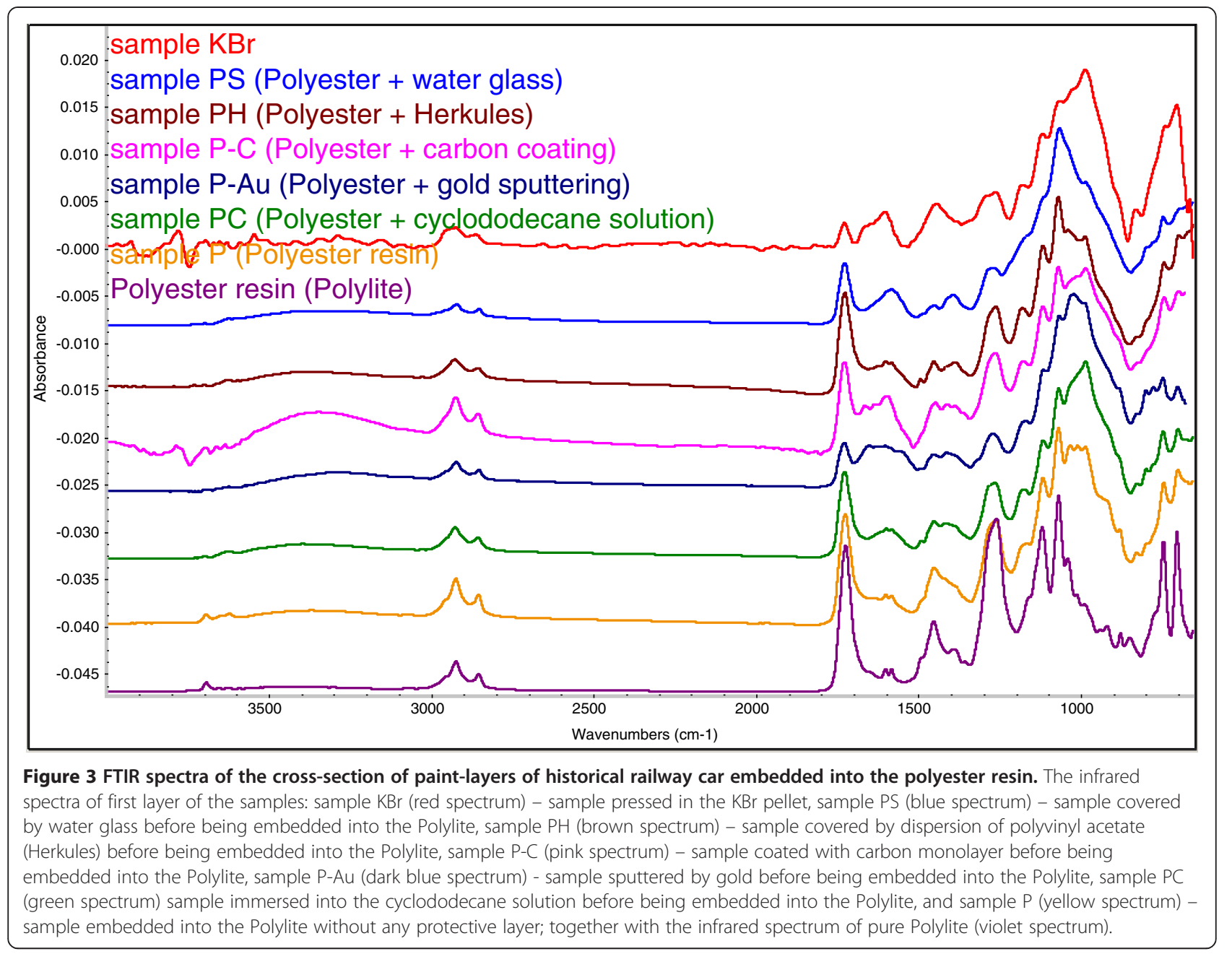

The disadvantage of this method is the intensive labour involved and the inconvenient storage the of hydroscopic $\mathrm{KBr}$ pellets (pellets must be stored in a desiccator when not in use). Considering the size of the sample elemental analysis of the sample in a pellet can be carried out only by micro methods such as SEM-EDX. Due to the fact that $\mathrm{KBr}$ does not penetrate into the sample, results are not affected by the presence of $\mathrm{KBr}$, if only points inside the layers of the sample are analysed.

\section{Polyacrylic resin Dentacryl}

Polyacrylic polymers have significant vibration bands at the $1727,1471,1393,1242,1176,1156,952$ and $747 \mathrm{~cm}^{-1}$ [18]. These bands may overlap, distort or disturb the vibration spectral bands of analysed sample embedded in Dentacryl. The Dentacryl infiltrates into the sample, as shown in Figure 2, where in the infrared spectrum of the surface layer of the sample embedded in Dentacryl (sample D - the dark blue spectrum) appear almost only spectral bands of Dentacryl (to compare with the lowest violet spectrum). This acrylic resin is not suitable for preparing samples of lacquer layers in form of polished cross-section.

\section{Polyester resin Polylite}

Polyester resin Polylite has strong vibration bands [18] at the 1718, 1268, 1105 and $729 \mathrm{~cm}^{-1}$. Polylite has higher molecular weight than the Dentacryl resin, inhibiting its infiltration into the pore system of the sample (density of Polylite is $1.12 \mathrm{~g} \cdot \mathrm{m}^{-3}$ and Dentacryl $0.95 \mathrm{~g} \cdot \mathrm{cm}^{-3}$ $[19,20])$. Therefore, Polylite was selected as an embedding material for further experiments. A slight amount of infiltration into the first layer of the embedded sample by the Polylite is evident (see spectral peaks at wave numbers 1722, 1598, 1580, 1259, 1114 and $1065 \mathrm{~cm}^{-1}$ on the yellow spectrum (sample P) in Figure 3) but the dominant vibration spectral bands belong to vibrations of molecules of the sample from the historical railway car.

Before being embedded in Polylite, the sample was covered with an insulating layer to minimize the infiltration into the outer layers. 


\section{The insulation of the sample from the polyester resin Liquid glass}

Water glass can be used to isolate non-porous samples, but after wet grinding the surface of the cross-section must be thoroughly washed with water and dried. However, even then spectra of the individual analysed layers may be distorted by strong absorption, which is a characteristic of silicates.

On the contrary, water glass is a simpler and safer option that significantly reduces the infiltration of the embedding resin into the sample (Figure 3 - sample PS).

\section{Aqueous dispersion of the polymer}

The benefit of using the aqueous dispersion of polyvinyl acetate (Herkules) as a protective layer of the sample is minimal. After wet grinding, the vinyl acetate polymer contaminates practically the entire area of the crosssection (much more than water glass). This procedure cannot be recommended (Figure 3 - sample PH).

\section{Gold sputtering or carbon coating}

Samples covered by a molecular layer of carbon or gold are well isolated from the embedding resin, providing that the sample is compact, without large open porosity or cracks. For analysis of coherent paint layers, this method appears to be the best possible solution. It is evident that the monatomic layer of gold is a better insulator than the carbon layer (Figure 3 - sample $\mathrm{P}$-Au and $\mathrm{P}-\mathrm{C})$. In the infrared spectrum of the sample $\mathrm{P}-\mathrm{Au}$ any significant vibration spectral bands belonging to vibrations of the molecules of polyester resin (violet spectrum) have been found.

\section{Cyclododecane in melted form or as solution}

Cyclododecane can be used successfully as a barrier between the sample and embedding material either as a melt or in the form of a concentrated solution (for example in white spirit). The cyclododecane solution covers the sample penetrating into its pores and cracks, while the cyclododecane in a melted form creates a relatively thick coating on the surface of the sample only. After this treatment the sample is embedded in synthetic resin.

Before FTIR analysis it is necessary to allow the evaporation of the cyclododecane from the open surface of the cross-section. This takes approximately $24 \mathrm{hrs}$. at room temperature but can be accelerated by hot air.

If the cyclododecane coating on the surface of the sample is too thick before embedding the sample in the resin (if melted cyclododecane was used), when the cyclododecane evaporates, the sample may be insufficiently fixed in the embedding resin. Therefore, it is preferable to use a cyclododecane solution (Figure 3 sample PC).
This method of preparation also reduces the contamination of samples embedded in acrylic resin (Dentacryl). It is, however, not a sufficient reduction of contamination. In Figure 2 you can see in infrared spectra of the sample DC and sample DCt spectral bands significant for acrylic resin $\left(1725 \mathrm{~cm}^{-1}\right.$ and $\left.1148 \mathrm{~cm}^{-1}\right)$.

The use of cyclododecane solution as an insulator is an effective method but the method of pressing the layered sample in $\mathrm{KBr}$ pellets which exclude contamination of the sample by any other compound remains superior.

\section{Reproducibility}

The reproducibility of the measurements (the FTIR spectra of the first layer of the samples) had also been tested. All procedures of preparing of the sample have been repeated five-times and the spectra of the first layer of the samples have been collected from 8 points of measurements on the average (in full length of the first layer of the sample). The reproducibility has been calculated as a percentage variance of the collected spectra and average spectrum of the first layer of the sample. The results are summarized in Table 2.

\section{Analysis of flesh of Madonna from a church of St. Thomas in Brno}

The confirmation of the advantage of the pressing samples into the $\mathrm{KBr}$ pellet compared to the embedding them in Polylite was determined by an analysis of paint layers (flesh) of a wood panel painting, "Madonna" (church of St. Thomas, Brno, Czech Republic.) This sample was split into two pieces; one was embedded into Polylite resin and the second one into $\mathrm{KBr}$ pellet. In Figure 4 the infrared spectrum of the flesh tone layer (incarnate) of the sample embedded into Polylite (the red spectrum) shows mainly spectral bands of polyester resin - 1723, 1600, 1580, 1261, 1120, 1067, 744 and $702 \mathrm{~cm}^{-1}$ (the blue spectrum). On the contrary, in the infrared spectrum of the flesh tone

\begin{tabular}{ll}
$\begin{array}{l}\text { Table } 2 \text { Reproducibility of the measurements of infrared } \\
\text { spectrum of the first layer of the samples }\end{array}$ \\
\hline Sample name & Average variance $\%$ (SD) \\
\hline Sample KBr & $1.52 \pm 1.07$ \\
Sample D & $5.76 \pm 3.89$ \\
Sample DC & $1.73 \pm 1.53$ \\
Sample DCt & $2.31 \pm 0.93$ \\
Sample P & $4.87 \pm 3.00$ \\
Sample PC & $5.40 \pm 3.66$ \\
Sample PCt & $8.19 \pm 4.30$ \\
Sample PS & $7.66 \pm 3.62$ \\
Sample PH & $7.23 \pm 3.33$ \\
Sample P-C & $7.03 \pm 3.67$ \\
Sample P-Au & $2.01 \pm 0.92$ \\
\hline
\end{tabular}




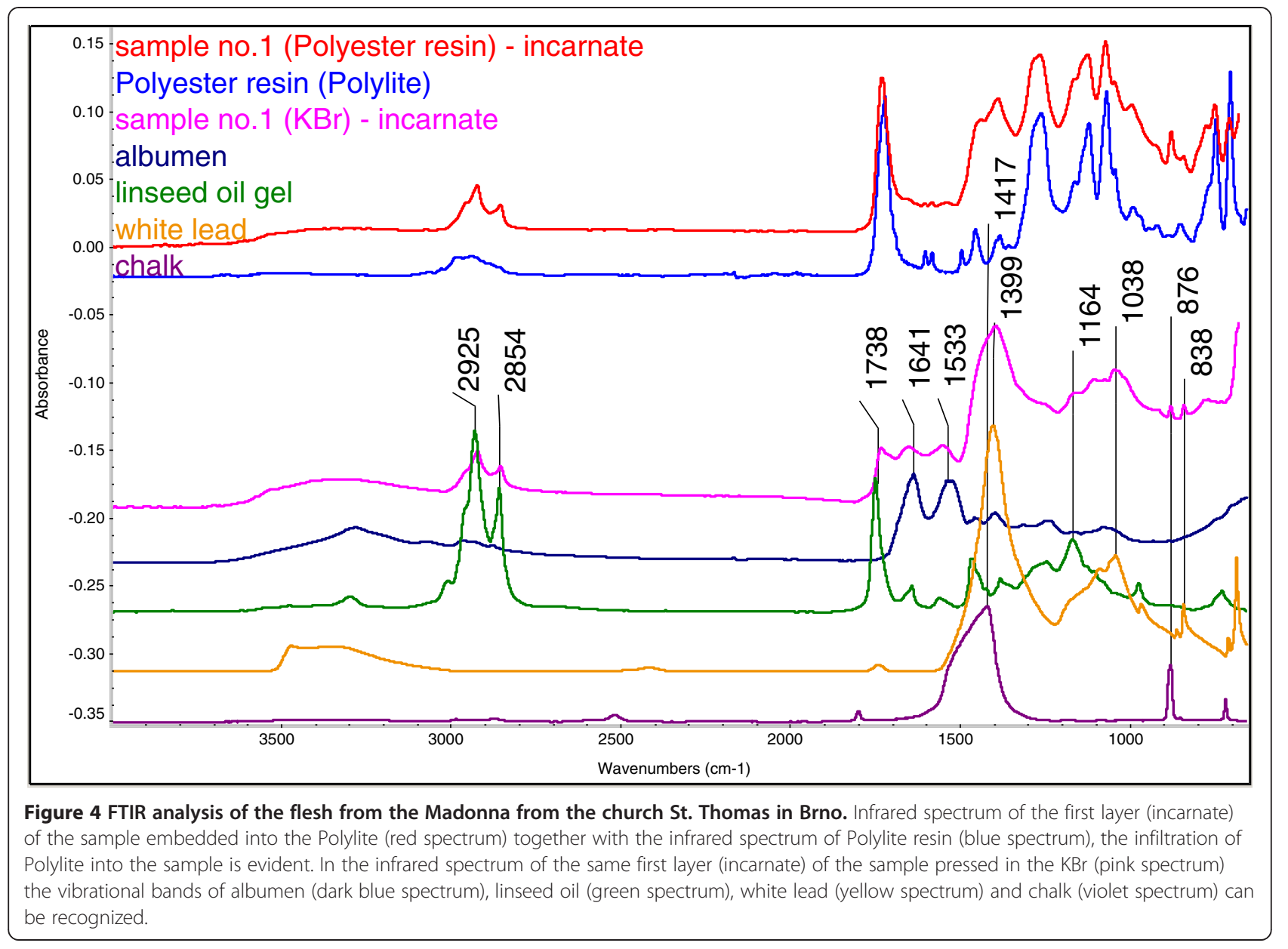

layer of the sample pressed into a $\mathrm{KBr}$ pellet (the pink spectrum), spectral bands specific for proteins (carbonyl group = amide $\mathrm{I}$ and $\mathrm{C}-\mathrm{N}-\mathrm{H}$ group $=$ amide II, vibration bands of 1641 and $1533 \mathrm{~cm}^{-1}$ ) and spectral bands specific for $\mathrm{C}-\mathrm{H}$ groups and ester/acid carbonyl (vibration bands of $2925,2854,1738$ and $1164 \mathrm{~cm}^{-1}$ ) can be recognized.
The presence of those spectral bands indicates the use of a binder consisting of a mixture of albumen and linseed oil. Spectral bands specific for pigments - white lead (vibration bands of 1399, 1038 and $838 \mathrm{~cm}^{-1}$ ) and chalk (vibration bands of 1417 and $876 \mathrm{~cm}^{-1}$ ) are clearly recognized, too [7].

Table 3 A critical comparison of the tested methods of sample preparation for FTIR analysis

\begin{tabular}{|c|c|c|c|c|c|c|}
\hline \multicolumn{2}{|c|}{ Method of sample preparation } & \multirow{2}{*}{$\begin{array}{l}\text { Cross-section compactness } \\
+\end{array}$} & \multirow{2}{*}{$\begin{array}{l}\text { No sample contamination } \\
\text { Limited }\end{array}$} & \multirow{2}{*}{$\begin{array}{l}\text { Archiving } \\
+\end{array}$} & \multirow{2}{*}{$\begin{array}{l}\text { Laboriousness } \\
+\end{array}$} & \multirow{2}{*}{$\frac{\text { Evaluation }}{2}$} \\
\hline Barrier methods & Silicate (Liquid glass) & & & & & \\
\hline & Dispersion of vinyl acetate & + & - & + & + & 5 \\
\hline & Cyclododecane - melt & - & Limited & Limited & + & 4 \\
\hline & Cyclododecane - solution & + & Limited & + & + & 2 \\
\hline & Carbon coating & + & + & + & - & 1 \\
\hline & Gold sputtering & + & + & + & - & 1 \\
\hline \multirow[t]{3}{*}{ KBr pellet } & Sample cut askew & + & + & Limited & - & 1 \\
\hline & Sample grind down in pellet & + & + & Limited & - & 1 \\
\hline & Twice moulded sample & + & + & Limited & - & 1 \\
\hline
\end{tabular}

Mark " 1 " belongs to the best, mark " 5 " to the worst one.

$+\ldots$ Method meets the requirement

- ... Method does not meet the requirement

Limited ... The requirement is only partially met

The methods are evaluated with respect to analysis accuracy. 


\section{Conclusions}

Various procedures used for sample preparation are discussed and sample preparations minimizing any contamination of these samples by their embedding material are proposed. The complete results of the applicability of these methods are listed in Table 3.

In terms of accuracy the positive results of the FTIR analysis were achieved with gold sputtered or carbon coated samples. This method of insulation is not suitable for samples with a large open porosity. Relatively good results were achieved with the use of a water glass solution or cyclododecane as an insulator, but this method of insulation may be influenced by the chemical nature of the sample.

The best methods are those which involve pressing the layered sample in $\mathrm{KBr}$ pellets. These methods eliminate the contamination of the sample by any other compound, regardless of the morphology of the sample (porous/non-porous, cracked, ...), and also regardless of its chemical nature. The disadvantage of these methods is the limited possibility to store $\mathrm{KBr}$ pellets (in a desiccator only).

This conclusion was confirmed by an analysis of paint layers (flesh) of wood panel painting - Madonna (church of St. Thomas, Brno, Czech Republic) embedded into Polylite as well as pressed into $\mathrm{KBr}$ pellet. The identification of the incarnate of the sample embedded into Polylite had not been possible (the spectrum consists mainly of polyester resin spectral bands), however in the spectrum of the incarnate pressed into $\mathrm{KBr}$ pellet, spectral bands specific for albumen, linseed oil, white lead and chalk can be clearly recognized.

\section{Competing interests}

The authors declare that they have no competing interests.

\section{Authors' contributions}

IK performed the sampling in situ. ES carried out the analysis. IK drafted the manuscript. Both authors read, revised critically and approved the final manuscript.

\section{Acknowledgements}

This work is financially supported by Ministry of Culture of the Czech Republic (Project NAKI DF12P01OW034 - Physical and Chemical Analytical methods, Their Application in the Research of Collection Items of the National Technical Museum with Regard to their Restoration and Preventive Conservation).

Received: 19 March 2014 Accepted: 16 September 2014

Published online: 02 October 2014

\section{References}

1. Rizzo A: Progress in the application of ATR-FTIR microscopy to the study of multi-layered cross-sections from works of art. Anal Bioanal Chem 2008, 392:47-55.

2. De Fonjaudran $C M$, Nevin A, Piqué F, Cather S: Stratigraphic analysis of organic materials in wall painting samples using micro-FTIR attenuated total reflectance and a novel sample preparation technique. Anal Bioanal Chem 2008, 392:77-86
3. Derrick M, Souza L, Kieslich T, Florsheim H, Stulik D: Embedding paint cross-section samples in polyester resins: Problems and solutions. J Am Inst Conserv 1994, 33:227-245.

4. Kovala-Demertzi D, Papathanasis L, Mazzeo R, Demertzis MA, Varella EA, Prati S: Pigment identification in a Greek icon by optical microscopy and infrared microspectroscopy. J Cult Herit 2012, 13:107-113.

5. Poli T, Chiantore O, Giovagnoli A, Piccirillo A: FTIR imaging investigation in MIR and in an enlarged MIR-NIR spectral range. Anal Bioanal Chem 2012, 402:2977-2984.

6. Ricci C, Bloxham S, Kazarian SG: ATR-FTIR imaging of albumen photographic prints. J Cult Herit 2007, 8:387-395.

7. Derrick MR, Stulik D, Landry JM: Infrared spectroscopy in conservation science: Scientific tools for conservation. Los Angeles: The Getty Conservation Institute; 1999:33-37.

8. SWGMAT: Forensic Paint Analysis and Comparison Guidelines. http:// www.swgmat.org/Forensic\%20Paint\%20Analysis\%20and\%20Comparison\% 20Guidelines.pdf.

9. Tahtouh M, Flynn K, Walker S, Roux C, Reedy B: FTIR spectral imaging applications in trace evidence. http://projects.nfstc.org/trace/docs/Trace\% 20Presentations\%20CD-2/Tahtouh.pdf.

10. Prati S, Rosi F, Sciutto G, Mazzeo R, Magrini D, Sotiropoulou S, Van Bos M: Evaluation of the effect of six different paint cross section preparation methods on the performances of Fourier transformed infrared microscopy in attenuated total reflection mode. Microchem J 2012, 103:79-89.

11. Flynn K, O'Leary R, Lennard C, Roux C, Reedy BJ: Forensic applications of infrared chemical imaging: Multi-layered paint chips. J Forensic Sci 2005, 50:832-841.

12. Van der Weerd J, Heeren RMA, Boon JJ: Preparation methods and accessories for the infrared spectroscopic analysis of multi-layer paint films. Stud Conserv 2004, 49:193-210.

13. Mazzeo R, Joseph E, Prati S, Millemaggi A: Attenuated total reflection-Fourier transform infrared microspectroscopic mapping for the characterisation of paint cross-sections. Anal Chim Acta 2007, 599:107-117.

14. Prati $S$, Joseph E, Sciutto G, Mazzeo R: New advances in the application of FTIR microscopy and spectroscopy for the characterization of artistic materials. Acc Chem Res 2010, 43:792-801.

15. MSDS - Potassium silicates (MR higher than 2,6). http://www.vodnisklo. cz/en/files/20110921094710.pdf.

16. Machovic V, Kopecky L, Nemecek J, Kolar F, Svitilova J, Bittnar Z, Andertova J: Raman micro-spectroscopy mapping and microstructural and micromechanical study of interfacial transition zone in concrete reinforced by poly(ethylene terephthalate) fibres. Ceramics-Silikáty 2008, 52:54-60.

17. Pitthard V, Griesser M, Stanek S, Bayerova T: Study of complex organic binding media systems on artworks applying GC-MS analysis: Selected examples from the Kunsthistorisches Museum, Vienna. Macromol Symp 2006, 238:37-45.

18. IRUG (Infrared and Raman Users Group) database. http://irug.org/.

19. Polylite ${ }^{\circledast 3}$ 32032-00. http://www.amtcomposites.co.za/sites/default/files/ media/data-sheets/POLYLITE\%2032032-00.pdf.

20. MSDS - Dentacryl, technical grade. www.spofadental.com/media/Products/ ProductFamily/359/en-US/Documents/40260/Dentacryls_MSDS_R9_EN.pdf.

doi:10.1186/s40494-014-0022-1

Cite this article as: Kopecká and Svobodová: Methodology for infrared spectroscopy analysis of sandwich multilayer samples of historical materials. Heritage Science 2014 2:22. 